Available online at GSC Online Press Directory

GSC Biological and Pharmaceutical Sciences

e-ISSN: 2581-3250, CODEN (USA): GBPSC2

Journal homepage: https://www.gsconlinepress.com/journals/gscbps

(RESEARCH ARTICLE)

\title{
Sedative and hypnotic effects of the roots of Asparagus africanus (Asparagaceae) decoction on white mice (Mus musculus Swiss)
}

\author{
Tchinmi Elisabeth ${ }^{1,}{ }^{*}$, Ngah Esther ${ }^{2}$ and Ngo Bum Elisabeth ${ }^{1}$ \\ ${ }^{1}$ Department of Biological Sciences, Faculty of Sciences, University of Ngaoundere, P.O. Box 454, Ngaoundere, Cameroon. \\ ${ }^{2}$ Department of Food Sciences and Nutrition, National School of Agro-Industrial Sciences, University of Ngaoundere, P.O. \\ Box 454 Ngaoundere, Cameroon.
}

Publication history: Received on 16 June 2020; revised on 26 June 2020; accepted on 27 June 2020

Article DOI: https://doi.org/10.30574/gscbps.2020.11.3.0189

\begin{abstract}
Asparagus africanus Lam. (Asparagaceae) is a plant widely used in traditional medicine as an anti-inflammatory, for the treatment of nervous disorders and insomnia. The aim of this work was to study the sedative and hypnotic effects of the roots of A. africanus decoction on white mice (Mus musculus Swiss). Sleep potentiation tests induced by diazepam and sodium pentobarbital were used. The sleep latency period onset and the sleep duration were recorded. The concentrations of GABA a[nd GABA-T in the brains of mice were also estimated. A. africanus significantly decreased the sleep latency period onset and increased the sleep duration induced by diazepam and sodium pentobarbital. Bicuculline, a competitive photosensitive antagonist of the GABAA receptor complex, did not prevent this potentiation. The effect of A. africanus on the sleep time was not blocked by flumazenil, a specific antagonist to the benzodiazepine site in the GABAA receptor complex. GABA increased and GABA-T decreased in the animals brain A. africanus treated significantly. Therefore the sedative properties of $A$. africanus might be possibly mediated by the activation of GABAergic neurotransmission on inhibitory receptors and by the decrease in the recapture of GABA by inhibiting GABA-T. These properties justified its use against insomnia in traditional medicine.
\end{abstract}

Keywords: Asparagus africanus; Diazepam; Pentobarbital sodium; Sedatives; Mice

\section{Introduction}

Insomnia is a degenerative disease that affects the central nervous system due to high excitement in the brain $[1,2]$. It is defined as a complaint of sleep failure but difficult to obtain, insufficient or non-recoverable [3]. Insomnia is a very common health problem that lowers the quality of life of the individual and has significant social and economic costs [2]. It has a prevalence of $35 \%$ worldwide, of which 9 to $10 \%$ are chronic cases and $25 \%$ are occasional cases [4]. The main causes of insomnia are: anxiety, depression and psychoses which impart excessive stress on the temporal lobes [5]. Patients with epilepsy often report non-restful sleep and daytime sleepiness which affects their life quality and can lead to even more seizures [6].

Insomnia is treated with sedatives such as barbiturates (phenobarbital), benzodiazepines (Diazepam) and new generation sleeping pills (zolpidem and zopiclone) [7]. Unfortunately, these sedatives are indeed responsible for phenomena of dependence, intoxication and amnesia. They aren't indicated in pregnancy and lactation as well as for children [7, 2]; hence the need to look for a substance that is efficient, without undesirable side effects and that can be used by all. Medicinal plant-based pharmacotherapy for neurological and psychiatric illnesses has progressed due to their lower undesirable side effects and better tolerance [8]. Plants have extraordinary therapeutic virtues and about $75 \%$ of the african population still relies on plants for illness treatment [9].

\footnotetext{
* Corresponding author: Tchinmi Elisabeth; Phone: (+237) 697187867; E-mail address: tchinmie@yahoo.fr
} 
Asparagus africanus Lam. is a plant which belongs to the family of Asparagaceae [10]. The aqueous and ethanolic extracts of the roots of $A$. africanus are antidiabetic, less toxic and rich in phenolic compounds, a potential source of natural antioxidants which could have a great therapeutic importance in the oxidative stress linked to degenerative diseases [11]. A. africanus is widely used in traditional medicine as an anti-inflammatory [12] for the treatment of nervous disorders and insomnia [13]. The objective of this work was therefore to assess the sedative and hypnotic effects of $A$. africanus on white mice (Mus musculus Swiss).

\section{Material}

\subsection{Plant material}

The roots of $A$. africanus were collected in the locality of Bini-Dang, in the Adamawa region (Cameroon). A sample supporting document has been deposited at the headquarters at the national herbarium in Yaoundé (Cameroon) under number 40168/HHC/Cam. The harvested roots of $A$. africanus were washed, dried at room temperature and then ground. $100 \mathrm{ml}$ of distilled water was added to $10 \mathrm{~g}$ of this powder and then brought to boil for 20 minutes on a hot plate set at $100^{\circ} \mathrm{C}$. After cooling, the solution was filtered using Wattman number 1 filter paper, then evaporated in an oven $\left(70^{\circ} \mathrm{C}\right)$ for $24 \mathrm{~h} .65 \mathrm{ml}$ of distilled water was added to the dry extract obtained constituting the mother solution, the dose of which is $254 \mathrm{mg} / \mathrm{kg}$. Dilution with distilled water was made to $1 / 2$ and $1 / 4$ to obtain the 127 and $63.5 \mathrm{mg} / \mathrm{kg}$ doses respectively.

\subsection{Animal material}

White mice (Mus musculus Swiss) of both sexes, weighing 20 to $28 \mathrm{~g}$ were used for the various tests. These mice were obtained at the National Veterinary Laboratory (LANAVET) of Garoua (North Cameroon) and further raised in a controlled environment (12 hours of darkness), with access to unlimited food and water. All experiments were performed in accordance with the Guide to the Care and Use of Laboratory Animals published by "National Institutes of Health of the United States" (NIH Publication No. 85-23, revised in 1996). In addition, the study protocol for the handling of animals and the procedure for the experiment were approved by the National Ethics Committee of Cameroon (Ref. No. FW-IRB00001954).

\subsection{Drugs}

Pentobarbital sodium (Sigma Chemical, USA); Diazepam (DZP), bicuculline (BIC), flumazenil (RO 151788), N-methyl-ßcarboline-3-carboxamide (FG 7142) (Sanofi-Synthelabo). All other chemicals and reagents used in the evaluation of the amount gamma-aminobutyric acid (GABA) and gamma-aminobutyric acid transaminase (GABA-T) in the brain are from Sigma Chemical, USA.

\section{Methods}

\subsection{Sleep potentiation test with diazepam}

The method used is that described by Beretz [14] and modified by Rakotonirina [15]. It consisted in inducing sleep in mice after intraperitoneal (i.p.) injection of DZP $50 \mathrm{mg} / \mathrm{kg}$ administration dose one hour after administration of 10 $\mathrm{ml} / \mathrm{kg}$ doses of the roots of $A$. africanus decoction $(63.5,127$ and $254 \mathrm{mg} / \mathrm{kg})$ and distilled water for the control batch. Within 2 to $5 \mathrm{~min}$ the mice lying on the side, eyelids closed, were asleep. This was characterized by the loss of the righting reflex, observed by tickling the mouse inner pavilion ear using horsehair. The sleep duration was the time that elapses between the moment when the mouse loses the righting reflex and that when the latter reappears (observed when the movement of the foreleg on the side of the tickled ear) [15].

\subsection{Sleep induction test with pentobarbital sodium}

Three batches of five mice had received $10 \mathrm{ml} / \mathrm{kg}$ the roots of $A$. africanus decoction at different doses $(63.5,127$ and $254 \mathrm{mg} / \mathrm{kg}$ ). The mice in the positive control batch had received $10 \mathrm{ml} / \mathrm{kg}$ of $3 \mathrm{mg} / \mathrm{kg}$ diazepam dose (i.p.) and the mice in the negative control batch had received distilled water. One hour later, a $42 \mathrm{mg} / \mathrm{kg}$ sodium pentobarbital dose (i.p.) was administered to each mouse to induce sleep. Sleep onset latency period and sleep duration were recorded. The interval between loss and recovery of the righting reflex was used as an index of hypnotic effect [16]. In antagonistic experiments, N-methyl-ß-carboline-3-carboxamide (FG7142, $10 \mathrm{mg} / \mathrm{kg}$, i.p.), a partial reverse agonist of benzodiazepine of the GABAA receptor complex, flumazenil (R0151788, $10 \mathrm{mg} / \mathrm{kg}$, i.p.), a specific benzodiazepine antagonist in the GABAA receptor complex and bicuculline (BIC, $5 \mathrm{mg} / \mathrm{kg}$, i.p.), a competitive photosensitive antagonist of GABAA receptors, were injected 15 minutes before the start of the administration of the various treatments (extract, 
distilled water and diazepam). The treatments were administered 1 hour before the sodium pentobarbital, the latency period and the duration of sleep were recorded [17].

\subsection{Gamma aminobutyric acid (GABA) amounts}

The amount of GABA in the hippocampus of mice was evaluated by the colorimetric technique of mouse brain homogenates described by Lowe [18]. The working reagent consisted of a mixture of $0.2 \mathrm{ml}$ of $0.14 \mathrm{M}$ ninhydrin solution prepared in a bicarbonate buffer solution ( $0.5 \mathrm{M}$; pH 9.9), and $0.1 \mathrm{ml}$ of glacial trichloroacetic acid (TCA) $10 \%$. A $100 \mu \mathrm{l}$ homogenate sample was taken and introduced into the working reagent, the mixture was incubated at $60{ }^{\circ} \mathrm{C}$ in a water bath for 30 minutes. After cooling, the mixture was added into $5 \mathrm{ml}$ of copper tartrate solution prepared from $0.16 \%$ disodium carbonate, $0.03 \%$ copper sulphate and $0.0329 \%$ tartaric acid. The whole mixture was kept at a temperature of $25^{\circ} \mathrm{C}$ for 10 minutes. The fluorescence resulting from the reaction between ninhydrin and GABA in the basic medium was measured using a spectrofluorimeter and was proportional to the concentration of GABA in the homogenates. A standard GABA solution was prepared parallelly from different GABA masses (50, 100, 150, 200, 250, 300, 350 and 400 $\mu \mathrm{g}$ ) which were each mixed with $1.5 \mathrm{mg}$ of glutamate dissolved in $0.1 \mathrm{ml}$ of $10 \%$ TCA. The concentration of GABA in the samples was determined by referring to the GABA calibration curve [19]. The content of GABA in the brain was expressed in $\mu \mathrm{g} / \mathrm{g}$ of brain tissue.

\subsection{Determination of gamma aminobutyric acid transaminase (GABA-T)}

The activity of GABA-T was evaluated by the colorimetric assay method of Nayak and Chatterjee [20]. $15 \mu$ mol of $\alpha$ oxoglutarate, $15 \mu \mathrm{mol}$ of GABA, $10 \mu \mathrm{g}$ of pyridoxal phosphate, $0.1 \mathrm{ml}$ of homogenate brain supernatant and $0.1 \mathrm{ml}$ of $5 \%$ methanol were introduced in the tubes. The final volume of the mixture was made up to $3 \mathrm{ml}$ with Tris- $\mathrm{HCl}$ buffer. The tubes were incubated at $37{ }^{\circ} \mathrm{C}$ for 30 minutes. The reaction was completed by adding $0.5 \mathrm{ml}$ of $20 \%$ glacial TCA. Just before recording, the absorbance of each sample was recorded at $610 \mathrm{~nm}$ after 30 and $90 \mathrm{~s}$ against a blank just after adding $1 \mathrm{ml}$ iron chloride $\left(12 \% \mathrm{FeCl}_{3}\right)$. The color of the complex formed by succinic semialdehyde acid and 3-methyl-2benzothia-zolone-2-hydrazone in the presence of $12 \% \mathrm{FeCl}_{3}$ was proportional to the concentration of GABA-T in the homogenates. The activity of GABA-T was estimated in $\mathrm{pg} / \mathrm{min} / \mathrm{g}$ of tissue according to the Beer-Lambert law.

\subsection{Statistical analysis}

The statistical analysis was carried out using GraphPad Prism software version 8.0.1. The results were expressed as mean \pm standard error (S.E.M). The different values were compared using analysis of variance (ANOVA) and Tukey's multiple comparison.

\section{Results}

\subsection{Effect of the roots of Asparagus africanus decoction on latency period of onset and sleep time by diazepam}

Table 1 shows that: $A$. africanus significantly reduced the latency period of onset $\left[(\mathrm{F}(3,16)=20.22 ; \mathrm{P}<0.001) ; \mathrm{R}^{2}=\right.$ $79.13 \%]$ and increased the sleep time $\left[(\mathrm{F}(3,16)=2765 ; \mathrm{P}<0.001) ; \mathrm{R}^{2}=99.81 \%\right]$ induced by diazepam a dosedependent manner compared to the negative control.

Table 1 Effect of the roots of Asparagus africanus decoction on latency period of onset of sleep and sleep time induced by diazepam

\begin{tabular}{llll}
\hline Treatment & Dose $(\mathrm{mg} / \mathbf{k g})$ & \multicolumn{2}{c}{ Sedative action } \\
\hline & & $\begin{array}{l}\text { Latency period of } \\
\text { onset of sleep (min) }\end{array}$ & Sleep time (min) \\
\hline DW & - & $5.39 \pm 0.46$ & $13.15 \pm 1.21$ \\
Aa & 63.5 & $2.80 \pm 0.51^{* * *}$ & $57.22 \pm 0.63^{* * *}$ \\
Aa & 127 & $2.86 \pm 0.43^{* * *}$ & $53.79 \pm 0.94^{* * *}$ \\
Aa & 254 & $3.22 \pm 0.92^{* * *}$ & $56.65 \pm 0.77^{* * *}$
\end{tabular}

The results are expressed as mean \pm S.E.M, $n=5 .{ }^{* * *} \mathrm{p}<0.00,1$ significant difference compared to the negative control. DW: negative control consisting of mice treated with distilled water, Aa: Asparagus africanus. 


\subsection{Effect of the roots of Asparagus africanus decoction on the latency period of onset of sleep and sleep time induced by pentobarbital sodium}

Table 2 shows a significant decrease in the latency period of onset $\left[(\mathrm{F}(4,20)=94.41 ; \mathrm{P}<0.001) ; \mathrm{R}^{2}=94.97 \%\right]$ and a significant increase of sleep time $\left[(\mathrm{F}(4,20)=2477 ; \mathrm{P}<0.001) ; \mathrm{R}^{2}=99.80 \%\right]$ of sodium pentobarbital-induced dosedependent for $A$. africanus, comparable to diazepam (positive control) compared to the negative control. This decrease and increase is also significant respectively for the latency period of onset of sleep $[(\mathrm{F}(4,36)=0.277 ; \mathrm{P}<0.05)]$ and for sleep time $[(\mathrm{F}(4,36)=1.45 ; \mathrm{P}<0.05)]$ in presence of flumazenil and of bicuculline, comparable to diazepam (positive control) in comparison to the negative control.

Table 2 Effect of the roots of Asparagus africanus decoction on the latency period of onset of sleep and the duration of sleep induced by sodium pentobarbital

\begin{tabular}{|c|c|c|c|}
\hline \multirow[t]{2}{*}{ Treatment } & Dose (mg/kg) & \multicolumn{2}{|c|}{ Sedative action } \\
\hline & & $\begin{array}{l}\text { Latency period of } \\
\text { onset of sleep (min) }\end{array}$ & $\begin{array}{c}\text { Total sleep time } \\
\text { (min) }\end{array}$ \\
\hline DW & - & $6.22 \pm 0.45$ & $12.95 \pm 1.16$ \\
\hline DW + FG 7142 & +10 & $7.18 \pm 0.49$ & $10.91 \pm 1.67$ \\
\hline DW + RO 151788 & +10 & $6.59 \pm 0.69$ & $11.72 \pm 1.74$ \\
\hline $\mathrm{DW}+\mathrm{BIC}$ & +5 & $7.08 \pm 0.64$ & $11.94 \pm 1.70$ \\
\hline $\mathrm{Aa}$ & 63.5 & $3.08 \pm 0.20^{* * *}$ & $55.17 \pm 0.92^{* * *}$ \\
\hline $\mathrm{Aa}$ & 127 & $2.65 \pm 0.33^{* * *}$ & $56.78 \pm 0.44^{* * *}$ \\
\hline Aa & 254 & $2.98 \pm 0.39^{* * *}$ & $56.01 \pm 1.02^{* * *}$ \\
\hline $\mathrm{Aa}+\mathrm{FG} 7142$ & $63.5+10$ & $6.70 \pm 0.16$ & $11.17 \pm 0.84$ \\
\hline $\mathrm{Aa}+\mathrm{RO} 151788$ & $63.5+10$ & $5.84 \pm 0.06^{*}$ & $14.53 \pm 1.25^{*}$ \\
\hline $\mathrm{Aa}+\mathrm{BIC}$ & $63.5+5$ & $6.34 \pm 0.25^{*}$ & $14.78 \pm 1.77^{*}$ \\
\hline $\mathrm{DZP}$ & 3 & $2.86 \pm 0.30^{* * *}$ & $56.66 \pm 0.58^{* * *}$ \\
\hline $\mathrm{DZP}+\mathrm{FG} 7142$ & +10 & $6.73 \pm 0.28$ & $11.56 \pm 0.54$ \\
\hline DZP + RO 151788 & +10 & $5.81 \pm 0.56^{*}$ & $14.46 \pm 1.44^{*}$ \\
\hline $\mathrm{DZP}+\mathrm{BIC}$ & +5 & $6.33 \pm 0.03^{*}$ & $14.77 \pm 1.72^{*}$ \\
\hline
\end{tabular}

The results are expressed as mean \pm S.E.M, $\mathrm{n}=5 .^{*} \mathrm{p}<0.05,{ }^{* * *} \mathrm{p}<0.001$, significant difference compared to the negative control. DW: negative control consisting of mice treated with distilled water. DZP: positive control consisting of mice treated with diazepam (3 mg/kg), FG 7142: Nmethyl-ß-carboline-3-carboxamide, RO 151788: flumazenil, BIC: bicuculline, Aa: Asparagus africanus.

\subsection{Effect of a decoction of the roots of Asparagus africanus on the concentration of gamma aminobutyric acid in the hippocampus of mice induced by diazepam}

Table 3 shows that: $A$. africanus increased significantly in the concentration of gamma aminobutyric acid $[(\mathrm{F}(3,16)=$ 201.7; $\mathrm{P}<0.001$ ); $\mathrm{R}^{2}=99.34 \%$ ] and decreased significantly in concentration of gamma aminobutyric acid transaminase $\left[(\mathrm{F}(3,16)=41.23 ; \mathrm{P}<0.001) ; \mathrm{R}^{2}=96.87 \%\right]$ induced by diazepam a dose-dependent manner compared to the negative control.

Table 3 Effect of the roots of Asparagus africanus decoction on concentration of GABA and activity of GABA-T induced by diazepam

\begin{tabular}{lllc}
\hline Treatment & Dose $(\mathbf{m g} / \mathbf{k g})$ & \multicolumn{2}{l}{ Concentration of GABA and activity of GABA-T } \\
\hline & & GABA $(\boldsymbol{\mu g} / \mathbf{g})$ & GABA-T $(\mathbf{p g} / \mathbf{m i n} / \mathbf{g})$ \\
\hline DW & - & $241.47 \pm 9.14$ & $118.38 \pm 12.86$ \\
Aa & 63.5 & $377.95 \pm 4.94^{* * *}$ & $42.98 \pm 5.24^{* * *}$ \\
Aa & 127 & $364.40 \pm 5.89^{* * *}$ & $61.29 \pm 3.07^{* *}$ \\
Aa & 254 & $337.26 \pm 2.73^{* * *}$ & $91.44 \pm 3.45^{*}$
\end{tabular}

The results are expressed as mean \pm S.E.M, $\mathrm{n}=5 .^{*} \mathrm{p}<0.05,{ }^{* *} \mathrm{p}<0.01{ }^{* * *} \mathrm{p}<0.001$, significant difference compared to the negative control. DW: negative control consisting of mice treated with distilled water, Aa: Asparagus africanus. 


\subsection{Effect of the roots of Asparagus africanus decoction on the concentration of gamma aminobutyric acid in the hippocampus of mice induced by sodium pentobarbital}

Table 4 shows a significant increase in the concentration of gamma aminobutyric acid $\left[(\mathrm{F}(4,20)=38.20 ; \mathrm{P}<0.001) ; \mathrm{R}^{2}\right.$ $=96.83 \%]$ and a significant decrease in concentration of gamma aminobutyric acid transaminase $[(\mathrm{F}(4,20)=42.18 ; \mathrm{P}$ $<0.001$ ); $\mathrm{R}^{2}=97.12 \%$ ] for $A$. africanus comparable to diazepam (positive control) compared to the negative control. $A$. africanus increase significantly the concentration of gamma aminobutyric acid $[(\mathrm{F}(4,36)=1.16 ; \mathrm{P}<0.05)]$ and significantly decreases the concentration of aminobutyric acid transaminase $[(\mathrm{F}(4,36)=0.92 ; \mathrm{P}<0.05)]$ in presence of flumazenil and bicuculline comparable to diazepam (positive control) compared to the negative control.

Table 4 Effect of a decoction of the roots of Asparagus africanus on the concentration of gamma aminobutyric acid and gamma aminobutyric acid transaminase induced by sodium pentobarbital.

\begin{tabular}{llll}
\hline Treatment & Dose $(\mathbf{m g} / \mathbf{k g})$ & GABA $(\boldsymbol{\mu g} / \mathbf{g})$ & GABA-T $(\mathbf{p g} / \mathbf{m i n} / \mathbf{g})$ \\
\hline DW & - & $229.87 \pm 24.88$ & $92.93 \pm 7.32$ \\
DW + FG 7142 & $-\quad+10$ & $215.87 \pm 12.04$ & $100.98 \pm 6.13$ \\
DW + RO 151788 & $-\quad+10$ & $216.42 \pm 4.45$ & $103.50 \pm 4.00$ \\
DW + BIC & $-\quad+5$ & $225.83 \pm 12.08$ & $107.05 \pm 3.98$ \\
Aa & 63.5 & $362.02 \pm 1.79^{* * *}$ & $30.26 \pm 2.92^{* * *}$ \\
Aa & 127 & $345.17 \pm 5.58^{* * *}$ & $41.52 \pm 3.00^{* * *}$ \\
Aa & 254 & $320.22 \pm 5.15^{* * *}$ & $36.97 \pm 8.07^{* * *}$ \\
Aa + FG 7142 & $63.5+10$ & $220.13 \pm 5.13$ & $94.57 \pm 7.29$ \\
Aa + RO 151788 & $63.5+10$ & $240.22 \pm 6.73^{*}$ & $85.59 \pm 6.78^{*}$ \\
Aa + BIC & $63.5+5$ & $250.72 \pm 3.70^{*}$ & $87.58 \pm 3.10^{*}$ \\
DZP & 3 & $370.00 \pm 12.73^{* * *}$ & $32.55 \pm 5.03^{* * *}$ \\
DZP + FG 7142 & $3+10$ & $223.02 \pm 3.19$ & $95.22 \pm 4.22$ \\
DZP + RO 151788 & $3+10$ & $240.75 \pm 3.70^{*}$ & $92.79 \pm 7.70$ \\
DZP + BIC & $3+5$ & $251.89 \pm 3.61^{*}$ & $92.09 \pm 3.71$
\end{tabular}

The results are expressed as mean \pm S.E.M, $n=5 .^{*} \mathrm{p} \leq 0.05,{ }^{* * *} \mathrm{p} \leq 0.001$ significant difference compared to the negative control. DW: negative control consisting of mice treated with distilled water. DZP: positive control consisting of mice treated with diazepam (3 mg/kg), FG 7142: Nmethyl-ß-carboline-3-carboxamide, RO 151788: flumazenil, BIC: bicuculline, Aa: Asparagus africanus.

\section{Discussion}

A. africanus roots decoction decrease in the latency period of onset of sleep and also significantly increased the duration of sleep induced by diazepam and sodium pentobarbital, which suggests sedative activity [21]. The sedative and hypnotic effects of a substance are recognized by its ability to promote falling asleep and, in general, to prolong the duration of sleep. The quality of sleep obtained is generally close to natural sleep [22]. Benzodiazepines and barbiturates are known to have sedative and hypnotic properties because of their ability to potentiate the duration of sleep [21, 23, 17]. A. africanus roots decoction acted in the same way, it would therefore have sedative and hypnotic properties.

Flumazenil, a specific antagonist at the benzodiazepine site in the GABAA complex receptor, blocks by competitive inhibition the effects exerted on the central nervous system by substances which act on the receptors of benzodiazepines. The hypnotic and sedative effects of benzodiazepines are quickly reversed by flumazenil [3]. However, the effect of $A$. africanus on reducing latency and increasing sleep duration was not antagonized by it. Bicuculline, a competitive antagonist sensitive to GABAA receptors, whose role is to block the inhibitory action of GABA receptors, has also not prevented this effect. A. africanus would therefore act directly on the GABAergic system [24, 25, 8, 17].

Benzodiazepines and barbiturates act directly on GABAergic receptors and interact with GABAA [3]. Binding GABA to the GABAA receptor increases permeability to chloride ions, which stabilizes the resting potential and induces neuronal inhibition. Thus, GABA will activate inhibitory receptors and thereby reduce the activity of the postsynaptic cell within a reasonable margin [26]. The sedative (for example diazepam) is known to have a pharmacological action by increasing the content of GABA in the brain [27, 25, 17]. It is also found that a decoction of the roots of $A$. africanus significantly increased the concentration of GABA in the brains of mice. 
Other pharmacological mechanisms occurring on the GABAergic pathway are evoked such as: the reduction of the recapture of GABA in the synaptic cleft, by inhibiting the degradation enzymes like GABA-T [3]. A. africanus also significantly decreased the concentration of GABA-T in the brains of mice, thereby preventing the breakdown of GABA and increasing its action. This again suggests a sedative action.

Altogether, we suggest that the action of $A$. africanus is correlated with an increase in the concentration of GABA and a decrease in GABA-T in the brain. The effectiveness of most herbal medicines is attributed to various active ingredients in combination. For example, saponins show antagonistic activity against amphetamines, a sedative property [23, 28, $29,17]$. It is therefore likely that $A$. africanus has saponins which contributes in part to the effects observed on the central nervous system.

\section{Conclusion}

Based on the above studies we concluded that: A. africanus roots decoction might contain bioactive substances which are hypnotic and sedative. These neuropharmacological properties are possibly mediated via GABAergic neurotransmission. This justifies its use in traditional medicine in the treatment of insomnia.

\section{Compliance with ethical standards}

\section{Acknowledgments}

The authors are very thankful to the Laboratory of Medicinal plants, Health and Galenic Fomulation, Faculty of Sciences, University of Ngaoundéré, P.O. Box 454 Ngoundéré, Cameroon, for supporting us by providing apparatus and drugs.

\section{Disclosure of conflict of interest}

Tchinmi Elisabeth, Ngah Esther and Ngo Bum Elisabeth declare that they have no conflict of interest.

\section{Statement of ethical approval}

The experiment was carried out at the Laboratory of Medicinal plants, Health and Galenic Fomulation, Faculty of Sciences, University of Ngaoundéré in accordance with approval by the National Ethics Committee of Cameroon (Ref. No. FW-IRB00001954).

\section{References}

[1] Broca L. (2007). Chemical model of epilepsy, brain and receptors. Achives of pharmacology, (357), 54-59.

[2] Wener-Karrer. (2008). Insomnia Chronique. Forum med Suisses, (23), 426-431.

[3] Jost J. (2018). The determinants of the therapeutic deficit of epilepsy: place of the quality of antiepileptics in subSaharan Africa. Doctoral thesis. University of Limoges, France, 29-55.

[4] Billiard M and Dauvilliers Y. (2004). Insomnia, Neurology 1. Ernaculam Medical Centre, Kerala, India, $209-222$.

[5] Brudeur N and Storeur JM. (2001). Behavioral disorders and restlessness intensive care. Update conferences, Scientific and medical edition, 449-466.

[6] Crespel A, Baldy-Moulinier M and Coubes P. (1998). The relationship between sleep and epilepsy in frontal and temporal lobe epilepsies: practical and physiopathologic considerations. Epilepsia, (39), 150-157.

[7] Royant-Parola S. (2007). Sleep mechanisms: rhythms and pathology. The apple tree, Paris, France, 400-407.

[8] Zhang J. (2004). Therapeutic effects of herbal extracts and constituents in animal models of psychiatric disorders. Life Sciences, (75), 1659-1699.

[9] Svoboda K and Svoboda T. (2000). Secretory structures of aromatic and medicinal plants. Ed: microscopix publication, 7-12.

[10] Hans DN. (1996). African ethanobotany, poisons and drugs, chemistry, pharmacology, toxicology. Medpharm, 1 edition, 287-293.

[11] Onyeka DO. (2014). An evaluation of the antidiabetic properties Asparagus africanus Lam. Root extracts. Magister technologiae. Central University of technology, Free State, South Africa, 5-22. 
[12] Hassan HS, Ahmadu AA and Hassan AS. (2008). Analgesic and anti-inflammatory activities of Asparagus africanus root extract. African Journal of Traditional, Complementary and Alternative Medicine, (1), 27-31.

[13] Grieve M. (1992). A modern herbal. Hafner Press, New York, United States, 574.

[14] Beretz A, Haag-Berrurier M and Anton R. (1978). Choice of pharmacological methods for the study of hawthorn activities. Medicinal Plants and Phytotherapies, (4), 305-314.

[15] Rakotonirina SV, Ngo Bum E and Bopelet M. (2001). Sedatives properties of the decoction of the rhizome of Cyperatus articulates. Fitoterapia, (72), 22-29.

[16] Gonzalez-Trujano ME, Navarrete CA, Reyes B and Hong E. (1998). Some pharmacological effects of the ethanol extract of leaves of Annona diversifolia on the central nervous system in mice. Phytotherapy Research, (2), 600602.

[17] Taïıwe SG, Ngo Bum E, Talla E, Dawe A, Moto OCF, Ngoupaye TG, Sidiki N, Dabole B, Dzeufiet DDP, Dimo T and De Waard M. (2012). Antipsychotic and sedative effects of the leaf extract of Crassocephalum bauchiense (Hutch.) Milne-Redh (Asteraceae) in rodents. Journal of Ethnopharmacology, (143), 213-220.

[18] Lowe IP, Robins E and Eyermen GS. (1958). The fluorimetric measurement of glutamic decarboxylase and its distribution in brain. Journal of neurochemistry, (3), 8-16.

[19] Sutton I and Simmonds M. (1974). Effects of acute and chronic pentobarbitone on the $\beta$ - aminobutyric acid system in rat brain. Biochem.Pharmacology, (23), 1801-1808.

[20] Nayak P and Chatterjee AK. (2001). Effects of aluminum exposure on brain glutamate and GABA systems: an experimental study in rats. Food and Chemical Toxicology, (12), 1285-1289.

[21] Fujimori H. (1995). Potentiation of barbital hypnosis as an evaluation method for Central Nervous System depressant. Psychopharmacology, (7), 74-77.

[22] Allain P. (2002). Allosteric receptors of the Gaba receptor. Extract from "Medicines" 3rd edition, 3-8.

[23] Amos S, Abbah J, Chindo B, Edmond I, Binda L, Adzu B, Buhari S, Odutola AA, Wambebe C and Gamaniel K. (2005). Neuropharmacological effects of the aqueous extract of Nauclea latifolia root bark in rats and mice. Journal of Ethnopharmacology, (97), 53-57.

[24] Evans AK and Lowry CA. (2007). Pharmacology of the b-Carboline FG 7142, a partial inverse agonist at the benzodiazepine allosteric site of the GABAA receptor: neurochemical, neurophysiological and behavioral effects. Central Nervous System Drug Reviews, (13), 475-501.

[25] Taïwe GS, Ngo Bum E, Dimo T, Talla E, Weiss N, Amadou D, Moto OFC, Sidiki N, Dzeufiet PD and De Waard M. (2010). Antidepressant, muscle relaxant and anti-anxiety-like effects of Nauclea latifolia Smith (Rubiaceae) roots extract in murine models. International Journal of Pharmacology, (4), 326-333.

[26] Baulac S, Isabelle A, Brice A and Le Guern E. (2001). Epilepsies, convulsions feverish and ion channels: the beginning of a long story. Medicine/Sciences, (17), 999-1007.

[27] Chapman AG, Meldrum BS and Mendes E. (1983). Acute anticonvulsant activity structural analog of valproic acid and change in brain GABA and aspartate content. Life Science, (32), 2023-2031.

[28] Dubois MA, Ilyas M and Wagner H. (1986). Cussonosides A and B, two triterpenessaponins from Cussonia barteri. Planta Medica, (56), 80-83.

[29] Wagner H, Ott S, Jurcic K, Morton J and Neszmelyi A. (1983). Chemistry 12C NMR study and Pharmacology of two saponins from Colubrina astiatica. Planta Medica, (48), 136-141.

\section{How to cite this article}

Tchinmi E, Ngah E and Ngo Bum E. (2020). Sedative and hypnotic effects of the roots of Asparagus africanus (Asparagaceae) decoction on white mice (Mus musculus Swiss). GSC Biological and Pharmaceutical Sciences, 11(3), 254260 . 